\title{
Intratesticular Injection of Hypertonic Saline : Non-Invasive Alternative Method for Animal Castration Model
}

\author{
Byung Kuk Kwak and ${ }^{\dagger}$ Sung-Ho Lee \\ Department of Life Science, Sangmyung University, Seoul 110-743, Republic of Korea
}

\begin{abstract}
Previous studies, including our own, have demonstrated that the intratesticular injection of hypertonic saline (20\%) decreased serum testosterone level which was similar to the surgical castration in the rat, showing the state of chemical castration. In the present study, we further verify the efficacy of this less invasive method as an alternative of surgical orchidectomy in the andrological field. Sterilized $20 \%$ saline was directly injected into the adult male rats (750 $\mu \mathrm{l}$ per testis). The tested rats were divided into 3 groups including intact group (intact), orchidectomy group (ORX) and saline injection group (SAL) after bilateral orchidectomy was performed at the same day of injection. All rats were sacrificed at 4 weeks after injection. The reproductive organs (testes, epididymis, seminal vesicles and prostates) were collected and used for DNA and protein pattern analyses. Also, patho-histological studies on the testes were performed. In contrast to the intact group, similar DNA damages of testis and seminal vesicle were appeared in ORX group and SAL group. The DNA degradations seemed to be the results of necrosis rather than apoptosis. In the protein pattern analysis, all the testing tissues exerted similar patterns in the ORX group and the SAL group compared to the those of intact group. Patho-histological studies revealed that severe degenerative changes in testicular seminiferous tubules and massive infiltration of immune cells in SAL group. The present study confirmed that direct injection of hypertonic saline into the testis caused the equivalent biochemical changes in the accessory sex organs as shown in the orchidectomized animals. These results suggest that hypertonic saline injection model could be a useful castration model which can substitute for surgical castration when its safety is secured through further study in the future.
\end{abstract}

Key words : Hypertonic saline injection, Intratesticular, DNA and protein patterns, Accessory sex organs, Necrosis, Orchidectomy, Chemical castration

\section{INTRODUCTION}

Orchidectomy (also spelled orchiectomy) is a surgical procedure to remove testes and thought to be the oldest method of castration. In urological field, this procedure extensively used if testis cancer and prostate cancer were suspected (Moul, 2007; Damber, 2005). More recently, chemical castration which eliminates androgen by using hormone analogs has been widely used in the researches and medical remedy (Damber, 2005). Both surgical and chemical castration methods, however, have critical disadvantages. Though the surgical procedure is effective, infection or bleeding can bring a serious condition and it is time-consuming (Jana \& Samanta, 2007). On the other hand, hormone-based chemical castration is expensive and not cost-effective, frequently exerting the drug resistance in long-term therapy (Oefelein \& Cornum, 2000).

Several laboratories have developed nonsurgical sterilization

\footnotetext{
Manuscript received 27 November 2013, Received in revised form 15 December 2013, Accepted 21 December 2013

${ }^{\dagger}$ Corresponding Author : Sung-Ho Lee, Department of Life Science, Sangmyung University, 7 Hongji-dong, Jongno-gu, Seoul 110-743, Republic of Korea. Tel. : +82-2-2287-5139, Fax : +82-2-2287-0048, E-mail : shlee@smu.ac.kr

This is an Open Access article distributed under the terms of the Creative Commons Attribution Non-Commercial License(http://creativecommons. org/licenses/by-nc/3.0) which permits unrestricted non-commercial use, distribution, and reproduction in any medium, provided the original work is properly cited.
} 
methods, mostly using single intratesticular injection of simple salt solutions such as calcium chloride $\left(\mathrm{CaCl}_{2}\right)$ and hypertonic saline (Jana \& Samanta, 2006, 2007; Emir et al., 2008; Kwak et al., 2010). In particular, chemoablation of testes with hypertonic saline solution was found effective and were guaranteed minimal safety not only in the rats but in the human patients (Emir et al., 2011). To ensure the successful development and application in medical and research fields, however, these chemo-sterilization methods need to be more precisely studied in patho-physiological aspects.

In the present study, we further verify the efficacy of the hypertonic saline injection method using protein and DNA gel electrophoretic analyses.

\section{MATERIALS \& METHODS}

\section{Animals}

Male Sprague-Dawley rats (5 months old) were obtained from DBL (Chungcheongbuk-do, Korea) and acclimated 1 week in our animal facility under conditions of 12-h light/dark cycle (lights on at 07:00 h) and constant temperature of $22 \pm 1^{\circ} \mathrm{C}$. Animal care and experimental procedures were approved by the Institutional Animal care and the use committee at the Sangmyung University (R-1301) in accordance with guidelines established by the Korea Food and Drug Administration.

Rats were divided into three groups including intact group (intact), orchidectomy group (ORX) and saline injection group (SAL). Sterilized 20\% saline was directly injected into the animals (750 $\mu \mathrm{l}$ per testis) using insulin syringe. Bilateral orchidectomy was performed at the same day of the saline injection. All rats were sacrificed at 4 weeks after the saline injection. The reproductive tissues(testes, epididymis, seminal vesicles and prostates) were collected and used for DNA and protein pattern analyses.

\section{Genomic DNA (gDNA) preparation}

Total DNAs were extracted using the G-DEX ${ }^{\mathrm{TM}} \mathrm{II}_{\mathrm{c}}$ genomic DNA extraction kit (iNtRON, Korea). Briefly, reproductive tissues were homogenized in cell lysis buffer using homogenizer (IKA, Germany). Homogenate was treated with RNase solution for $30 \mathrm{~min}$ at $37^{\circ} \mathrm{C} .100 \mu \mathrm{l}$ of protein precipitation (PPT) buffer was added to the homogenate, and the homogenate was vigorously vortexed at high speed for 20 seconds. After vortexing, the homogenate was centrifuged at 12,000 rpm for 5 minutes and transferred the $300 \mu \mathrm{l}$ of supernatant to a $1.5 \mathrm{ml}$ tube. $300 \mu \mathrm{l}$ of $100 \%$ Isopropanol (Merck, Germany) was added to the sample and the sample was centrifuged at 12,000 rpm for 1 minute. The DNA pellet was dried and washed with $1 \mathrm{ml}$ of $70 \%$ ethanol. Finally, $150 \mu \mathrm{l}$ of DNA rehydration buffer was added to the extracted DNA and the resuspended samples were loaded into $2 \%$ agarose gels and separated by electrophoresis.

\section{SDS polyacrylamide gel electrophoresis (PAGE)}

The tissues were immediately placed in cold RIPA buffer [50 mM Tris (Biopure, Korea; pH 7.4), $150 \mathrm{mM} \mathrm{NaCl}$ (Sigma, USA), 1\% Triton X-100 (Sigma, USA), 1 mM Phenylmethylsulfonyl fluoride(PMSF)(Sigma, USA)] and homogenized. The homogenate was centrifuged at 13,000 rpm for 20 minutes at $4^{\circ} \mathrm{C}$ and the supernatant was transferred to a new $1.5 \mathrm{ml}$ tube. Protein quantity of the sample was measured using Bradford quantitative analysis method. After adding of 5X SDS dye, the protein samples were heated for 5 minutes at $90^{\circ} \mathrm{C}$ and stored at $-20^{\circ} \mathrm{C}$ for further analysis. The protein samples were warmed up to $37^{\circ} \mathrm{C}$, loaded into $10 \%$ polyacrylamide gels and were separated by electrophoresis for 2 hours at $100 \mathrm{~V}$. The total protein amount in each sample was adjusted by staining with Gelcode Coomassie Blue Stain Reagent (BioRad, USA) in order to provide equal loading.

\section{Histology}

Testes were fixed $4 \%$ paraformaldehyde overnight at $4^{\circ} \mathrm{C}$ for $24 \mathrm{~h}$, and then were serially dehydrated in graded ethanol and xylene. The fixed tissue were dehydrated in ethanol $(70 \%, 80 \%, 90 \%, 95 \%, 100 \%)$ and embedded in paraffin block. The tissues blocks were cut at 4-5 $\mu \mathrm{m}$ 
using microtome (HM350S, MICROM, Germany). Sections were stained with hematoxylin-eosin and observed using a light microscope (BX51, Olympus, Japan).

\section{RESULTS}

The first experiments were designed to compare the gDNA patterns of reproductive tissues and to elucidate if their pattern was differentially altered by the androgen deprivation methods (Fig. 1). We failed to observe the DNA ladder, a typical sign of apoptotic DNA fragmentation, in all samples (Fig. 1A-D). The gDNA gel electrophoresis of rat testes revealed that there was no breakdown of the gDNA in intact testes while broad range of ethidium bromide gDNA staining in the SAL group testes (Fig. 1A). In epididymal gDNA study, control group shown intact state of gDNA while those from ORX group and SAL group exerted the broken gDNAs which were more moderate than in saline injected testes (Fig. 1B). Similar pattern of gDNAs were found in seminal vesicles (Fig. 1C). However, the gDNAs from all three group shown intact state (Fig. 1D).

The second experiments were patho-histological approach to find whether the tissue gDNA pattern changes induced by hypertonic saline injection are correlated with degeneration testicular microstructure. While testes of the intact group were observed normal seminiferous tubules (Fig. 2), almost all testicular tissue underwent severe destruction with massive infiltration of immune cells in SAL group (Fig. 2).

The third experiments were protein pattern analysis. The proteins from testes (A), epididymi (B), seminal vesicles (C) and prostates (D) were collected and separated using SDS PAGE gel electrophoresis (10\%) (Fig. 3). When hypertonic saline was injected to the rats, the testes displayed the approximately $80 \mathrm{kD}$ protein band which was not found in intact testes. Also, 90-150 kD and 20-25 kD protein bands of intact testes were disappeared and decreased in SAL group testes, respectively (Fig. 3A). When compared to the epididymal protein pattern of intact group, the patterns of ORX group and SAL group were slightly

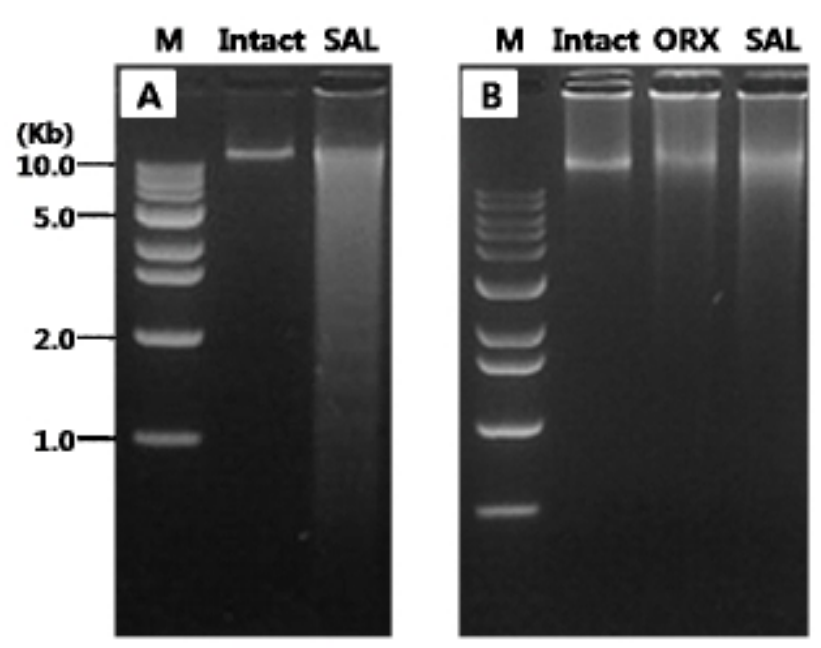

$M$ Intact ORX SAL $M$ Intact ORX SAL

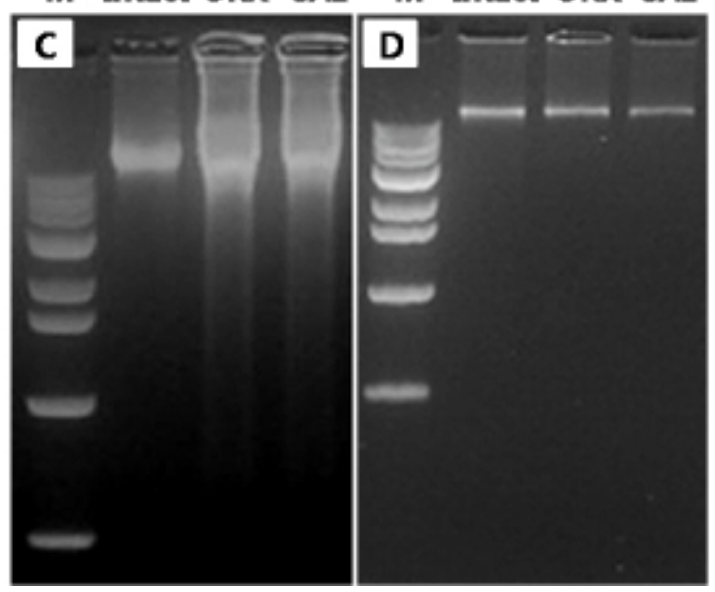

Fig. 1. DNA electrophoresis of testis (A), epididymis (B), seminal vesicle (C) and prostate gland (D). Rats were received a single bilateral injection (750 pl) of normal saline (Intact) or a single bilateral intratesticular injection of $20 \%$ hypertonic saline (SAL). As a second control, orchidectomy (ORX) was performed on the same day. 4 weeks later, genomic DNAs were extracted and separated by $2 \%$ agarose gels electrophoresis. The DNAs were visualized by ethidium bromide staining. M: size marker.

different (Fig. 3B). Approximately $72 \mathrm{kD}$ bands in epididymis of both ORX group and SAL group shown higher concentration than that in intact epididymis. The concentration of $20 \mathrm{kD}$ band was markedly reduced in ORX group and SAL group compared to intact group. There was no difference in the epididymal protein patterns between ORX group and SAL group. Similarly, the protein patterns of seminal vesicle and prostate from ORX group and SAL group were almost identical and shown little difference 


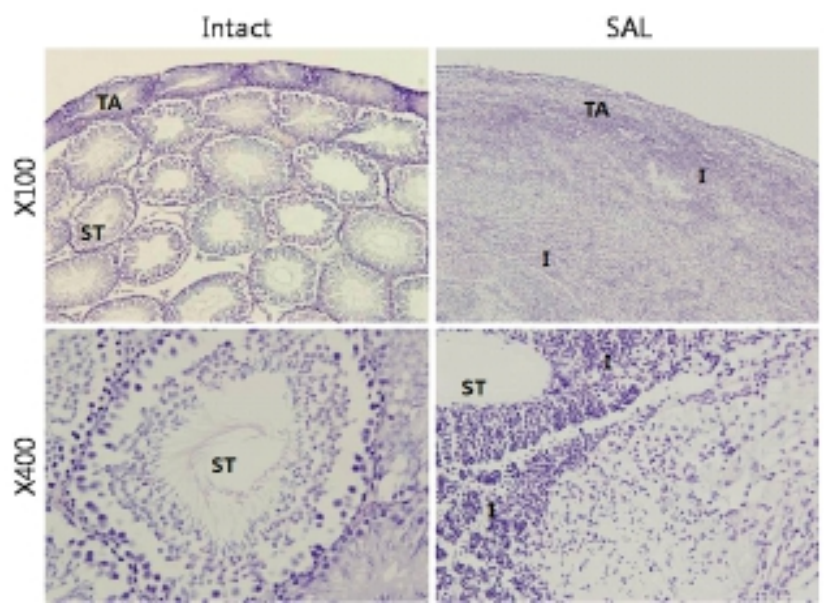

Fig. 2. Light microphotographs of the testes from the normal saline (Intact, left column) and $20 \%$ hypertonic saline (SAL, right column) treated adult rats. The cross sections were stained with hematoxylin and eosin (magnification, $\times 100$ and $\times 400$ ). ST, seminiferous tubules; TA, tunica albuginea; I, massive infiltration.
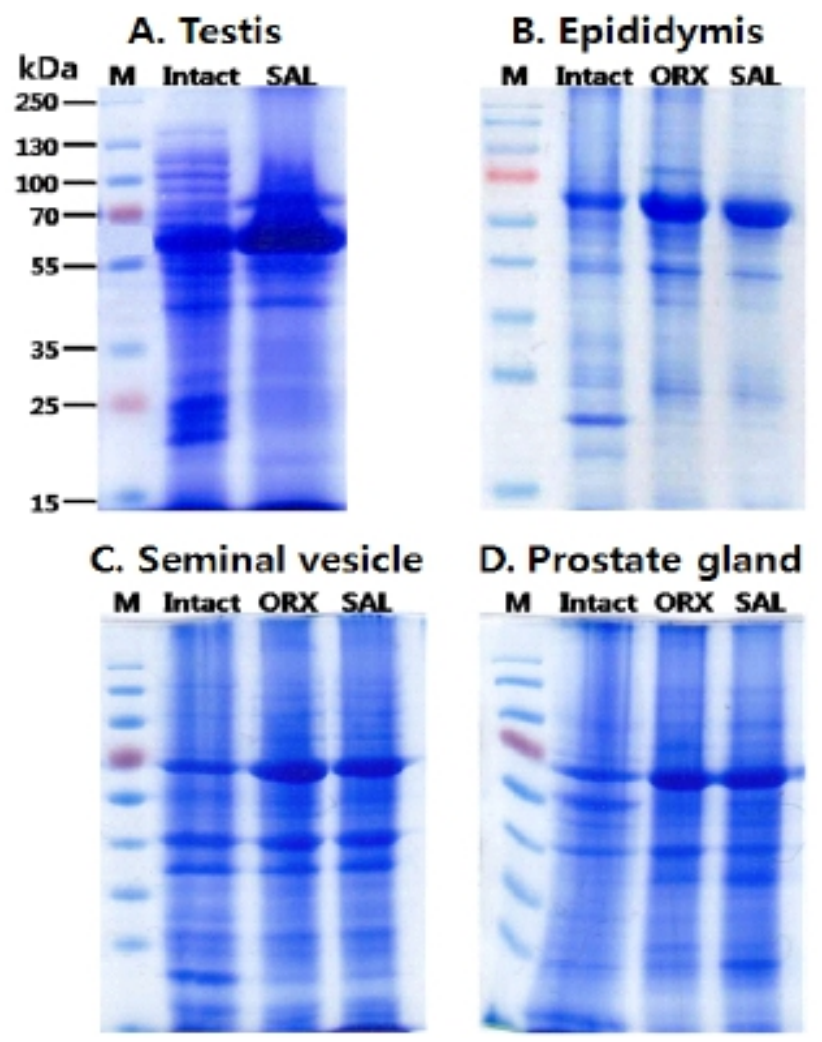

Fig. 3. Coomassie blue stained SDS-PAGE of proteins from testis (A), epididymis (B), seminal vesicle (C) and prostate gland (D). Rats were received a single bilateral injection $(750 \mu \mathrm{l})$ of normal saline (Intact) or a single bilateral intratesticular injection of $20 \%$ hypertonic saline (SAL). As second control, orchidectomy (ORX) was performed on the same day. M: size marker. between that of intact group (Fig. 3C \& D). In both ORX group and SAL group, $72 \mathrm{kD}$ band of seminal vesicle had higher concentration than that in intact epididymis. Same difference of band pattern was seen in prostate proteins. The concentrations of seminal vesicle $20 \mathrm{kD}$ band were markedly reduced in ORX group and SAL group compared to intact group, as shown in epididymal proteins (Fig. 3C). In the prostate samples, the concentrations of $60 \mathrm{kD}$ band were markedly reduced in ORX group and SAL group compared to intact group. The concentrations of $30 \mathrm{kD}$ band, on the other hand, were increased in ORX group and SAL group (Fig. 3D).

\section{DISCUSSION}

Bilateral orchidectomy, an endocrine treatment that depleting gonadal androgens, is the initially described hormonal treatment in prostate cancer and still constitutes the major castration method in developing countries (Emir et al., 2008). It is still considered as an important treatment method because of its direct and permanent effectiveness. However, infection or bleeding can become a problem and it is also time consuming, and is difficult for large-scale application, especially for controlling the population of undesirable mammals like pet animals (Jana \& Samanta, 2007).

Medical or chemical castration is another well-known endocrine treatment method. An ideal chemical sterilizing agent would be one that effectively arrests spermatogenesis and androgenesis as well as libido and absence of toxic and untoward side effects (Wiebe \& Barr, 1984). GnRH analogues such as degarelix are used to manage prostate cancer by desensitizing hypothalamus-pituitary-testis reproductive hormonal axis, and finally reducing the androgen action on the growth of prostate cancer cells (Steinberg, 2009). This chemical castration method is working in a reliable manner, but is very expensive.

Because simple salt solutions are inexpensive and easy to sterilization, some researchers have tested the efficacy of the solution as chemical sterilizing agent. A single bilateral intratesticular injection of $\mathrm{CaCl}_{2}$ solution resulted 
in induction of irreversible chemo-sterilization in male albino rats (Jana et al., 2002; Jana \& Samanta, 2006). The rats exhibited the germ cell depletion as well as significant diminution in serum testosterone concentration without any pain, stress response and any toxic and unwanted side effects (Jana et al., 2006 \& 2007). More recently, single dose of bilateral Intratesticular injection of hypertonic saline (20\%) successfully decreased serum testosterone level which was similar to the surgical castration in the rat, showing the state of chemical castration (Emir et al., 2008; Kwak et al., 2010).

Patho-histological studies revealed that intratesticular injection of hypertonic saline resulted in severe degenerative changes in testicular seminiferous tubules and massive infiltration of immune cells. The hypertonic saline may immediately create local osmotic shock and extensive necrotic state. Necrosis is a form of cell death as a consequence of extreme physico-chemical stress which kill cells quickly and directly (Kaczmarek et al., 2013). Therefore necrosis has been considered as uncontrolled death characterized by cellular collapse, though nuclei remain intact (Krysko et al., 2008). Recent evidence indicates that some immune substances and patho-physiological conditions can induce necrosis that follows defined steps and signaling events (Vanden Berghe et al., 2010). Necroptosis, a newly coined term describing the regulated necrosis, can be mediated through a pathway that depends on the receptor-interacting protein kinase (RIPK) 1-3 (Galluzzi \& Kroemer, 2011).

On the other hand, apoptosis, another type of cell death, has been widely accepted as a major mechanism of regulated cell death, employed not only upon accidental cell damage or stress but also during normal development (Nikoletopoulou et al., 2013). In the present study, hypertonic saline injection did not bring gDNA fragmentation, a key feature of apoptosis, in the accessory sex organs. The gDNA patterns in the androgen-sensitive organs were almost identical between ORX group and hypertonic saline injection group.

Using in vitro epididymis incubation and [35S] methionine incorporation technique (Jones et al., 1980), demonstrated that the radioisotope incorporation was reduced to $10 \%$ of that in normal tissues but could be restored to control levels by testosterone treatment. The authors found that the 18.5, 19.0 and $32 \mathrm{kD}$ proteins in the caput part and the $47 \mathrm{kD}$ protein in the cauda were preferentially regulated by androgens. In the present study, the $18.5-19 \mathrm{kD}$ protein band was markedly reduced in ORX group and hypertonic saline injection group compared to intact group.

In conclusion, we demonstrated that the hypertonic saline injection could result in very similar effects on rat accessory sex organs as surgical orchidectomy.

Our study suggests that the bilateral intratesticular injection of hypertonic saline may be considered as an alternative to surgical and chemical castration methods which are widely used in the field of andrology.

\section{ACK NOWLEDGEMENTS}

This research was supported by a 2013 Research Grant from Sangmyung University.

\section{REFERENCES}

Brito LF, Sertich PL, Rives W, Knobbe M, Del Piero F, Stull GB (2011) Effects of intratesticular zinc gluconate treatment on testicular dimensions, echodensity, histology, sperm production, and testosterone secretion in American black bears (Ursus americanus). Theriogenology 75:1444-1452.

D'Agostino A, Jones R, White R, Parker MG (1980) Androgenic regulation of messenger RNA in rat epididymis. Biochem J 190(3):505-512.

Damber JE (2005) Endocrine therapy for prostate cancer. Acta Oncol 44(6):605-609.

Emir L, Dadali M, Sunay M, Erol D, Caydere M, Ustün $\mathrm{H}$ (2008) Chemical castration with intratesticular injection of $20 \%$ hypertonic saline: a minimally invasive method. Urol Oncol 26(4):392-396.

Emir L, Sunay M, Yalbuzdağ O, Karakaya Y, Erol D (2011) Hormonal and pathologic changes after chemoablation 
BK Kwak, S-H Lee

of testes with hypertonic saline solution as a treatment method alternative to orchiectomy in patients with hormone sensitive metastatic prostatic cancer. Urol Oncol 29:212-217.

Galluzzi L, Kroemer G (2011) Necroptosis turns TNF lethal. Immunity 35(6):849-851.

Jana K, Samanta PK (2006) Evaluation of single intratesticular injection of calcium chloride for nonsurgical sterilization in adult albino rats. Contraception 73(3): 289-300.

Jana K, Samanta PK (2007) Sterilization of male stray dogs with a single intratesticular injection of calcium chloride: a dose-dependent study. Contraception 75:390400.

Jana K, Samanta PK, Ghosh D (2002) Dose-dependent response to an intratesticular injection of calcium chloride for induction of chemosterilization in adult albino rats. Vet Res Commun 26(8):651-673.

Jones R, Brown CR, Von Glós KI, Parker MG. (1980) Hormonal regulation of protein synthesis in the rat epididymis. Characterization of androgen-dependent and testicular fluid-dependent proteins. Biochem J 188(3): 667-76.

Kaczmarek A, Vandenabeele P, Krysko DV (2013) Necroptosis: the release of damage-associated molecular patterns and its physiological relevance. Immunity 38(2):209-223. Krysko DV, Vanden Berghe T, D'Herde K, Vandenabeele P (2008) Apoptosis and necrosis: detection, discrimination and phagocytosis. Methods 44(3):205-221.

Kwak BK, Lee C-S, Lee S-H (2010) Histological changes in rat testis by injection of hypertonic saline. Dev Reprod 14:281-286.
Moul JW (2007) Timely diagnosis of testicular cancer. Urol Clin North Am 34(2):109-117.

Nikoletopoulou V, Markaki M, Palikaras K, Tavernarakis N (2013) Crosstalk between apoptosis, necrosis and autophagy. Biochim Biophys Acta 1833(12):3448-3459.

Oefelein MG, Cornum R (2000) Failure to achieve castrate levels of testosterone during luteinizing hormone releasing hormone agonist therapy: the case for monitoring serum testosterone and a treatment decision algorithm. J Urol 164(3 Pt 1):726-729.

Oliveira EC, Moura MR, de Sá MJ, Silva VA Jr, Kastelic JP, Douglas RH, Marques AP Jr (2012) Permanent contraception of dogs induced with intratesticular injection of a zinc gluconate-based solution. Theriogenology 77:1056-1063.

Steinberg M (2009) Degarelix: a gonadotropin-releasing hormone antagonist for the management of prostate cancer. Clin Ther 31(Pt 2):2312-2331.

Toney TW, Danzo BJ (1989) Estrogen and androgen regulation of protein synthesis by the immature rabbit epididymis. Endocrinology 125(1):231-242.

Vanden Berghe T, Vanlangenakker N, Parthoens E, Deckers W, Devos M, Festjens N, Guerin CJ, Brunk UT, Declercq W, Vandenabeele P (2010) Necroptosis, necrosis and secondary necrosis converge on similar cellular disintegration features. Cell Death Differ 17(6):922-930. Wiebe JP, Barr KJ (1984) The control of male fertility by 1,2,3-trihydroxypropan (THP; glycerol): rapid arrest of spermatogenesis without altering libido, accessory organs, gonadal steroidogenesis and serum testosterone. LH and FSH. Contraception 29:291-302. 